\title{
ВЛАДЕНИЕ ИНОСТРАННЫМ ЯЗЫКОМ КАК НЕОТЬЕМЛЕМАЯ ЧАСТЬ МЕЖКУЛЬТУРНОЙ КОММУНИКАЦИИ
}

\section{FOREIGN LANGUAGE PROFICIENCY AS AN INTEGRAL PART OF INTERCULTURAL COMMUNICATION}

\section{E. Nikulina}

Summary: The recognition of the absolute value of the diversity of the world 's cultures, the rejection of colonizing cultural policies, the awareness of the fragility of existence and the threat of the destruction of the vast majority of traditional cultures and languages have led to the development of the relevant disciplines on the basis of the new phenomenon of interest of the peoples of the Earth in each other in the history of mankind.

Keywords: Intercultural communication, comparative cultural studies, contrasting pragmatics, awareness of language learning, practical communication needs.

\author{
Никулина Елена Валентиновна \\ К.и.н., доцент, Российский экономический университет \\ им. Г.В. Плеханова, филиал в г. Пятигорске \\ lena_nikulina1976@mail.ru
}

Аннотация: Признание абсолютной ценности разнообразия мировых культур, отказ от колонизаторской культурной политики, осознание хрупкости существования и угрозы уничтожения огромного большинства традиционных культур и языков привели к тому, что соответствующие дисциплины стали бурно развиваться, опираясь на новый в истории человечества феномен интереса народов Земли друг к другу.

Ключевые слова: межкультурная коммуникация, сравнительная культурология, контрастивная прагматика, осознание необходимости изучения языков, практические потребности в коммуникации.
$\mathrm{B}$ настоящее время всё чаще доминирует динамическое понимание культуры как образа жизни и система поведения, норм, ценностей и т. д. любой социальной группы (например, городская культура, культура поколений, культура организации). Динамическое понятие культуры не предполагает строгой стабильности культурной системы, она до определённой степени может меняться и модифицироваться в зависимости от социальной ситуации. Термин «межкультурная коммуникация» в узком смысле появился в литературе в 1970х годах. В известном учебнике Л. Самовара и Р. Портера «Коммуникация между культурами» (Communication between Cultures), впервые опубликованном в 1972, приводится определение: According to Samovar, Porter, McDaniel, and Roy, how people think and how they speak are determined to a large extent by their cultural identity. They argue that the knowledge and information that is communicated in language is an artifact of language itself since language is constituted to identify and give meaning to human experience (Samovar et. al, 2012, pp. 143-151). Martin and Nakayama (2008, p. 87) considered linguistic identity as individuals' self-concept, how they think they are as people. Language as a tool of communication helps the group's institutions to function because it infiltrates the core of cultural and ethnic identities without people's awareness (Joseph, 2004, p. 15). К этому времени сформировалось и научное направление, сердцевиной которого стало изучение коммуникативных неудач и их последствий в ситуациях межкультурного общения. Впоследствии произошло расширение понятия межкультурной коммуни- кации на такие области, как теория перевода, обучение иностранным языкам, сравнительная культурология, контрастивная прагматика и др. К настоящему моменту научные исследования в области межкультурной коммуникации фокусируются на поведении людей, сталкивающихся с культурно-обусловленными различиями в языковой деятельности и последствиями этих различий. Результатами исследований стали описания культурной специфики при выражении и интерпретировании ситуативных языковых действий коммуникантов[1]. С самого начала эти исследования имели большое прикладное значение и использовались в многочисленных разработках для практических занятий (тренингов) по развитию кросс-культурной восприимчивости. Межкультурная коммуникация как общественный феномен была вызвана к жизни практическими потребностями послевоенного мира, подкреплявшимися идеологически тем интересом, который с начала 20 в. формировался в научной среде и в общественном сознании по отношению к так называемым «экзотическим» культурам и языкам. Практические потребности возникли вследствие бурного экономического развития многих стран и регионов, революционных изменений в технологии. В результате мир стал значительно меньше - плотность и интенсивность продолжительных контактов между представителями разных культур очень выросли и продолжают увеличиваться.

Помимо собственно экономики - важнейшими зонами профессиональной и социальной межкультурной 
коммуникации стали образование, туризм, наука. Эти практические потребности были поддержаны изменениями в общественном сознании и, в первую очередь, постмодернистским отказом от европоцентристских подходов в гуманитарных и общественных науках. Признание абсолютной ценности разнообразия мировых культур, отказ от колонизаторской культурной политики, осознание хрупкости существования и угрозы уничтожения огромного большинства традиционных культур и языков привели к тому, что соответствующие дисциплины стали бурно развиваться, опираясь на новый в истории человечества феномен интереса народов Земли друг к другу. Становление межкультурной коммуникации как учебной дисциплины первоначально было обусловлено сугубо практическими интересами американских политиков и бизнесменов. После Второй мировой войны активно расширялась сфера влияния американской политики, экономики и культуры. Правительственные чиновники и бизнесмены, работавшие за границей, часто обнаруживали свою беспомощность и неспособность разобраться в ситуациях непонимания, возникавших при работе с представителями других культур. Нередко это приводило к конфликтам, взаимной неприязни, обидам. Даже совершенное знание соответствующих языков не могло подготовить их к сложным проблемам работы за границей. Постепенно возникло осознание необходимости изучения не только языков, но и культур других народов, их обычаев, традиций, норм поведения. Процесс становления межкультурной коммуникации как учебной дисциплины начался в 1960-е годы, когда этот предмет стал преподаваться в ряде университетов США. Это обстоятельство существенно изменило содержание учебного курса межкультурной коммуникации. В 1970-е годы сугубо практический характер курса был дополнен необходимыми теоретическими обобщениями и приобрел форму классического университетского курса, сочетающего в себе как теоретические положения, так и практические аспекты межкультурного общения[3]. В отечественной науке и системе образования инициаторами изучения межкультурной коммуникации стали преподаватели иностранных языков, которые первыми осознали, что для эффективного общения с представителями других культур недостаточно одного владения иностранным языком. Практика общения с иностранцами доказала, что даже глубокие знания иностранного языка не исключают непонимания и конфликтов с носителями этого языка. For Americans, excessive autonomy and connection were significant predictors of relationship satisfaction. As a society leaning towards individualistic tendencies, maintaining a separate identity as an individual (as opposed to a group level identity) is an important aspect of individual expression (Hofstede, 2001; Samovar, Porter, McDaniel, \& Roy, 2013). Thus, it is not surprising that excessive connection emerged as a significant, negative predictor to relationship satisfaction, while excessive autonomy on the other hand, emerged as a significant, positive predictor to relationship satisfaction[9]. Поэтому преподавание иностранных языков во многих вузах дополнилось предметом «Страноведение», который знакомит студентов с историей, обычаями, традициями, социальной организацией страны изучаемого языка. Однако, как показала практика, только аудиторного (теоретического) знакомства с соответствующей культурой оказывается недостаточно для бесконфликтного общения с ее представителями. Сегодня стало очевидным, что успешные и эффективные контакты с представителями других культур невозможны без практических навыков в межкультурном общении. В ряде российских вузов в учебные планы включена новая дисциплина «Межкультурная коммуникация». Введение этой дисциплины обусловлено, прежде всего, необходимостью подготовить студентов к эффективным межкультурным контактам на уровне повседневного межличностного общения. Для этого недостаточно лишь знаний о природе межкультурного непонимания, здесь необходимо формирование практических навыков и умений, которые позволили бы свободно понимать представителей других культур. В настоящее время межкультурная коммуникация только начинает утверждаться в российских вузах в качестве учебной дисциплины. Инициатором и бесспорным лидером в этом процессе является факультет иностранных языков МГУ, где межкультурная коммуникация преподается на протяжении нескольких лет и где уже разработан ряд лекционных курсов и программ по различным аспектам этого направления. Инициатива факультета нашла поддержку в ряде других московских вузов: университете Дружбы народов, Государственном лингвистическом университете, Российском государственном гуманитарном университете. Опыт преподавания межкультурной коммуникации в этих вузах показывает, что наиболее эффективным является сочетание лекционных и практических форм занятий. [8] Особую эффективность доказали практические занятия, в ходе которых студенты получают возможность испытать чувства и эмоции, возникающие в реальных ситуациях межкультурной коммуникации, обсудить и проанализировать свое собственное поведение и поведение своих партнеров. Практические занятия, как правило, вызывают оживленные дискуссии, значительно повышают мотивацию и заинтересованность студентов в предмете, устраняют психологический барьер во взаимодействии студентов и преподавателя. Осваивая каждый новый язык, человек расширяет не только свой кругозор, но и границы своего мировосприятия и мироощущения. То, как он воспринимает мир, и что он в нем видит, всегда отражается в понятиях, сформированных на основе человека исходного языка и с учетом всего многообразия присущих этому языку выразительных средств. Более того, ни одна ситуация не воспринимается человеком беспристрастно. Они оцениваются им, равно как и явления иных культур, всегда через призму принятых в родном лингвосоциуме культурных норм и ценностей, 
через призму усвоенной индивидуумом модели миропонимания. Познавательные процессы в культурном контексте исследовались К. Леви-Строссом, А.Р. Лурией и другими. Исследователей интересовала именно социокультурная специфика познавательных процессов, в том числе и в компаративном ключе[8]. Есть убеждения, что культура отражается на познавательной специфике личности и так или иначе формирует ее когнитивный стиль. Безусловно, существуют и другие модели классификации культур, используемые в культурологии, социологии, философии, психологии, кросс-культурном менеджменте. Приведенные выше модели дают наиболее системное представление о дифференцированной сути культур. Далее, рассмотрим более подробно, каким образом данные культурологические особенности влияют на мышление и деятельность индивидов, принадлежащих к разным культурным группам. А. Вежбицкая в своих работах также исследует влияние различий в культуре на отличительные особенности в мышлении через национальный язык. Она утверждает, что успешная коммуникация между отдельными культурами напрямую зависит от универсальности базового множества семантических примитивов, из которых каждый язык может создавать практически бесконечное число специфичных для данной культуры понятий. Имеющийся набор семантических примитивов, совпадающий с набором лексических универсалий примитивов, образует целое поле примитивов-универсалий, что является основой межкультурной коммуникации. В этом случае языковая специфика конфигураций данных примитивов лежит в основе дифференциации культур.

Опираясь на исследования А. Лурии, Вежбицкая утверждает, что различные способы мышления не делают человеческие культуры взаимно непроницаемыми, если общими являются исходные понятийные ресурсы. Интересно то, что через понятия и степень их выраженности можно судить о специфике когнитивных процессов. По мнению польской исследовательницы, у западных народов слова думать и знать имеют когнитивный смысл, а у не западных они присутствуют в языке, но имеют более простое понимание.[4]

Л. Леви-Брюль утверждал, что в традиционных, не западных культурах ментальность мало использует абстракцию, а если и использует, то по-другому, нежели мозг, находящийся во власти логического мышления. В культурологических исследованиях используется термин культурная схема, который означает комплексы предположений или ожиданий, усваиваемых индивидами, управляющие вниманием, помогающие делать логические выводы о ситуации, реконструирующие память и являющиеся базой для интерпретации настоящего. Культурные схемы возникают из опыта, проинтерпретированного в соответствии с коллективной историей и традицией, и представляют собой мощные культурные и психологические феномены. Понятие культурная схема использовалось для объяснения различия или сходства в сравнении дискурсов культур « важным разделом науки, связанным с межкультурной коммуникацией, лингвистикой, теорией коммуникации, психологией и рядом других наук является лингвистическая прагматика. Термин прагматика введен в конце 30-х гг. XX в. Чарльзом Уильямом Моррисом как название одного из разделов семиотики - науки о знаках. Семиотика, по Моррису, распадается на три составляющие: семантику, изучающую отношение знаков к объектам, синтактику - раздел о межзнаковых отношениях, и прагматику, исследующую отношение говорящих к знакам. Лингвистическая прагматика (лингвопрагматика) - это дисциплина, изучающая способность человека выражать с помощью лингвистических и паралингвистических средств свои намерения и понимать намерения собеседника (т. е. понимать, зачем и почему собеседник произнес то или иное высказывание), исходя из контекста, в котором было произнесено высказывание. Лингвистическая прагматика изучает также способы, с помощью которых человек достигает коммуникативных целей[2].

Уже сегодня очевидно, что межкультурная составляющая учебного процесса диктует необходимость поиска новых психолого-педагогических, методических решений. Эти решения связаны с моделированием систем обучения иностранному языку как процессу приобщения индивидуального опыта общения с чужой лингвокультурой. Учащиеся, сопоставляя различные концептуальные системы, обогащают свое сознание за счет интернационализации мира за пределами своей родной культурной реальности и средств, и структурирования. Одним из ведущих принципов обновленного процесса межкультурного образования в средней школе становится принцип культуросообразности. Это означает, что воспитание учащихся основывается на общечеловеческих ценностях и строится в контексте диалога своей страны и культуры стран изучаемого языка. В этой связи предмет Иностранный язык занимает особое место. Для того чтобы познакомить учащихся с достижениями культуры стран изучаемого языка преподавателю практически на любом занятии иностранного языка необходимо вводить страноведческий и лингвострановедческий компоненты. Эти социокультурные знания о мире, эти когнитивные знания принято называть фоновыми знаниями. Считается, что в общем плане обучение иностранным языкам должно подразумевать приобщение к языковому сознанию народа - носителя языка. Для примера возьмем правила речевого этикета. Русские при встрече и прощании пожимают руку, но у англичан такое не принято, даже для деловых людей. Англичанин поздоровается с вами за руку только при первом знакомстве, а в остальных случаях, при встрече обменяется с вами парой дружеских слов. Таким образом, обучение общению на иностранном языке в подлинном смысле этого слова 
подразумевает овладение социокультурными знаниями и умениями. Без этого нет и не будет практического овладения языком. Из этого следует, что культуроведческая направленность обучения ИЯ обеспечивает реализацию не только общеобразовательных и воспитательных целей (как и на других учебных предметах), но также вполне конкретных практических целей. Одна из важнейших задач преподавателя - необходимость разработки технологии обучения социокультурному компоненту в содержании обучения ИЯ. При этом не следует забывать о родной культуре учащихся, привлекая ее элементы для сравнения, - поскольку только в этом случае обучаемый осознает особенности восприятия мира представителями другой культуры. [2] Задачи преподавателя научить: понимать устные и письменные сообщения по темам, предусмотренным программой; правильно и самостоятельно выражать свои мысли в устной и письменной форме; критически оценивать предлагаемый материал и активно работать с ним; использовать соответствующую справочную литературу и словари; отстаивать свою точку зрения и осознанно принимать собственное решение; выполнять проектные работы и рефераты; работать самостоятельно и в коллективе [1] Г.Д. Томахин в своих исследованиях утверждает, что существует необходимость отбирать и изучать языковые единицы, в которых четко проявляется своеобразие национальной культуры и которые невозможно понять так, как их понимают носители данного языка. Эти слова можно встретить во всех случаях общения с представителями других культур, при чтении прессы, публицистики, художественной литературы, просмотре видеофильмов. В число лексических единиц, обладающих выраженной культурной семантикой Г.Д. Томахин включает: 1) названия реалий, - обозначение явлений, характерных для одной культуры, которые отсутствуют в другой: топонимы (географические понятия). Географические названия могут быть известны за пределами данной страны. Ассоциации, связанные с этими объектами, являются частью национальной куль- туры и могут быть неизвестны за пределами данной культуры; антропонимы (имена людей). В первую очередь это имена исторических и государственных деятелей; этнографические реалии: пища, одежда, праздники, транспорт, деньги; общественно-политические реалии; реалии системы образования; реалии, связанные с культурой: театр, кино, литература, музыка, изобразительное искусство. 2) коннотативная лексика, та лексика, которая совпадает по значению, но отличается по культурным ассоциациям; 3) фоновая лексика - обозначает явления, которые имеют аналогию в сопоставимой культуре, но имеют различия в национальных особенностях. Для лингвострановедения также большой интерес представляют фразеологизмы, в которых отражается национальное своеобразие культуры, традиций, образа жизни, истории народа - носителя языка. Пословицы для лингвострановедения также представляют немалый интерес. В пословицах заключена мудрость народа, его умение тонко подмечать отдельные стороны жизни человека, где раскрывается его наблюдательность и способность кратко выражать свое отношение к окружающему миру в целом[7].

По мнению Пассова Е.И. язык человека является средством осмысления этого мира, он вбирает и преломляет всю совокупность знаний и представлений о мире. С одной стороны, язык есть порождение самой культуры и средство её выражения. С другой стороны - это часть культуры [7, с.10-19]. Поэтому овладение иностранным языком - это не просто приобретение ещё одного психологического инструмента, но приобщение к иной культуре, овладение новым социокультурным содержанием, и в этом контексте обучение иностранному языку рассматривается как диалог двух культур (своей собственной и иноязычной) в общем формате межкультурного общения (равноправное культурное взаимодействие представителей разных лингвокультурных общностей с учётом их самобытности и своеобразия).

\section{ЛИТЕРАТУРА}

1. Гузикова М.0. Основы теории межкультурной коммуникации : учебное пособие для вузов / М.0. Гузикова, П.Ю. Фофанова. — Москва: Издательство Юрайт, 2020. — 121 с. — (Высшее образование). — ISBN 978-5-534-09551-7. — Текст : электронный // ЭБС Юрайт [сайт]. c. 54 — URL: https://biblioonline.ru/bcode/454632/p.54 (дата обращения: 11.03.2020).

2. Теория межкультурной коммуникации: учебник и практикум для вузов / Ю.В. Таратухина [и др.] ; под редакцией Ю.В. Таратухиной, С.Н. Безус. —- МоСКва : Издательство Юрайт, 2020. — 265 c. — (Высшее образование). — ISBN 978-5-534-00365-9. — Текст : электронный // ЭБС Юрайт [сайт]. с. 36 — URL: https://biblio-online.ru/bcode/450778/p.36 (дата обращения: 10.03.2020).

3. Барышников Н.В. Параметры обучения межкультурной коммуникации в средней школе. - 2002. - № 2.

4. Белая Е.Н. Теория и практика межкультурной коммуникации: учебное пособие / Е.Н. Белая; Федер. агентство по образованию, Гос. образоват. учреждение высш. проф. образования Омский гос. ун-т им. Ф. М. Достоевского -- Омск : Изд-во ОмГУ , 2008 - 207 с.

5. Головлева Е.Л. Основы формирования межкультурной компетентности у молодежи: Учеб.-метод. комплекс для работников в сфере молодежной политики, преподавателей, организаторов межкультурного и межконфессионального обучения молодежи .- М. : Ин-т междунар. соц.-гуманит. связей , 2005: ПИК ВИНИТИ - 181 с.

6. Исмаилов В.В. Глобалистический подход в обучении иностранным языкам. //Высшее образование сегодня . 2007. - №6 - С. 40-42 11. Караулов Ю.Н. 
Русский язык и языковая личность. - М.: Наука, 1987. - 263 с.

7. Подопригора С.Я. Образование и межкультурная коммуникация: [монография] / С.Я. Подопригора, Т.Г. Первиль; Федеральное агентство по образованию, Гос. образовательное учреждение высш. проф. образования Донской гос. технический ун-т. - Ростов-на-Дону : ДГТУ, 2006 (Ростов н/Д: ИЦ ДГТУ). - 160 с.

8. Россия и англоязычный мир: проблемы межкультурной коммуникации: монография / Кубанев Н.А. [и др.]; Гос. образовательное учреждение высшего проф. образования «Арзамасский гос. пед. ин-т им. А.П. Гайдара». - Арзамас: АГПИ им. Гайдара, 2006 (Арзамас : Участок офсет. печати). - 118 с.

9. https://www.researchgate.net/publication/281976681_Communication_Between_Cultures_9th_edition

ОНикулина Елена Валентиновна (lena_nikulina1976@mail.ru).

Журнал «Современная наука: актуальные проблемы теории и практики»

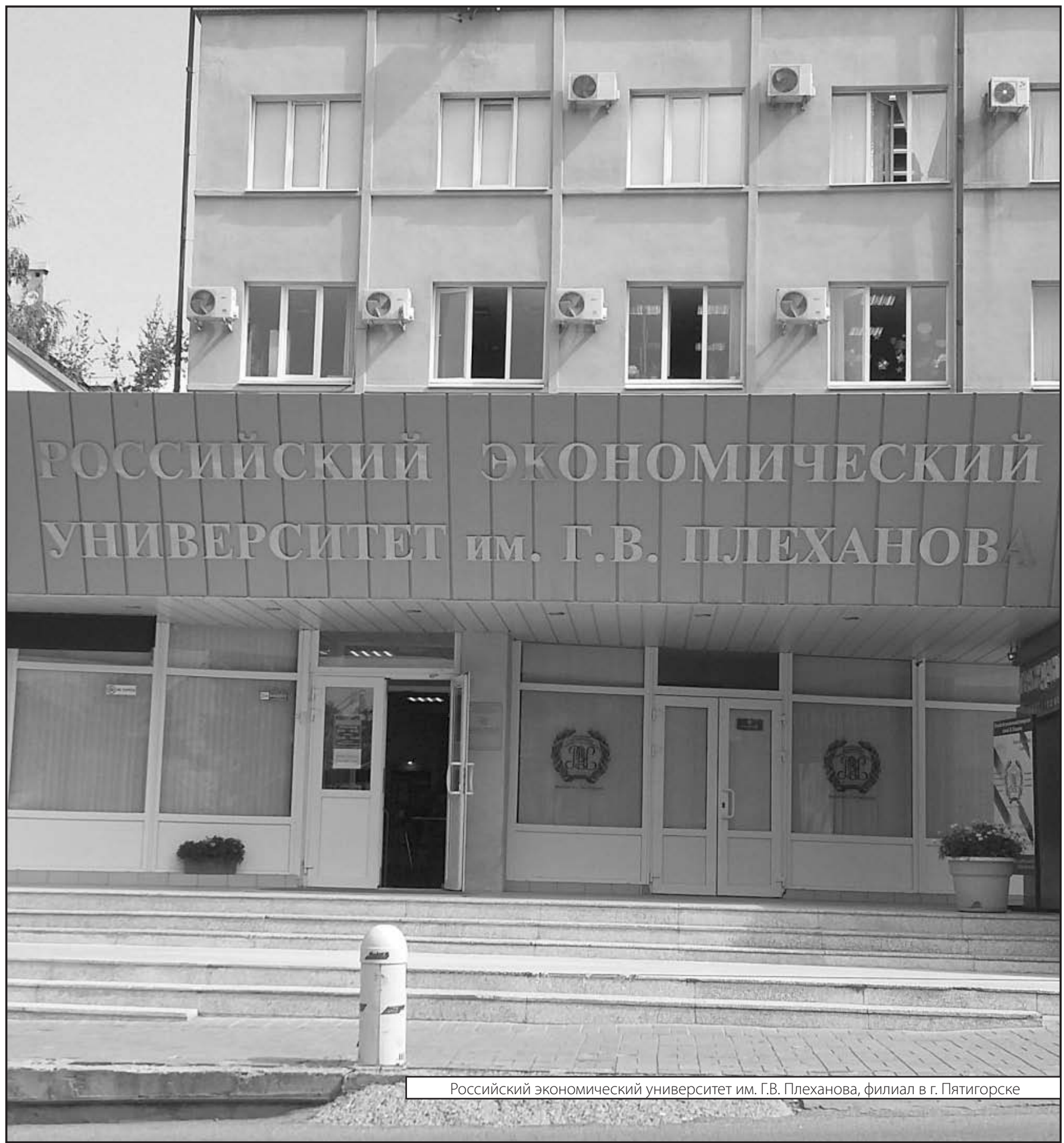

